\title{
Initial experience with the Heartstring proximal anastomotic system
}

\author{
Benjamin Medalion, MD \\ David Meirson, MD \\ Eli Hauptman, MD \\ Lior Sasson, MD \\ Arie Schachner, MD
}

From the Department of Cardiothoracic Surgery, The Edith Wolfson Medical Center, affiliated with Sackler School of Medicine, Tel Aviv University, Holon, Israel.

Received for publication Sept 4, 2003; revisions requested Oct 3, 2003; accepted for publication Nov 4, 2003.

Address for reprints: Benjamin Medalion, MD, Department of Cardiothoracic Surgery, The Edith Wolfson Medical Center, PO Box 5, Holon, Israel 58100 (E-mail: medalion@wolfson.health.gov.il).

J Thorac Cardiovasc Surg 2004;128:273-7

$0022-5223 / \$ 30.00$

Copyright $\odot 2003$ by The American Association for Thoracic Surgery

doi:10.1016/j.jtcvs.2003.11.045
Objective: Manipulation of the aorta has been shown to be associated with postoperative neurologic events after surgical myocardial revascularization when the aorta is diseased. The Heartstring proximal anastomotic system (Guidant, Indianapolis, Ind) is a device designed to assist in the performance of proximal anastomoses with minimal aortic manipulation. We describe our initial experience with this product.

Methods: Twelve patients with a diseased aorta who underwent off-pump myocardial revascularization and had their proximal anastomoses performed with the Heartstring device were studied for operative and postoperative outcomes and surgical technique.

Results: The mean age of the patients was $76 \pm 7$ years. The estimated EuroSCORE perioperative mortality was $12 \% \pm 8 \%$. The median number of distal anastomoses was 3 . In all patients, a saphenous vein graft was anastomosed to the aorta using the Heartstring device. In 5 patients, the radial artery was used as a conduit and connected proximally to a left internal thoracic artery as a Y graft, to a saphenous vein graft as a "horseshoe," or on the hood of a saphenous vein graft. The operative and postoperative courses were uneventful. Three seals developed cracks and were not used. One seal developed an unravel in its periphery but was used successfully.

Conclusions: The Heartstring proximal anastomotic system is a device that allows the surgeon to perform standard proximal clampless anastomoses. Elderly patients with a diseased aorta may benefit from this device.

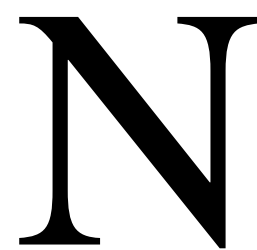

eurologic events after surgical myocardial revascularization are devastating complications to the patient, family, and care provider. Performing the operation without the use of cardiopulmonary bypass (off-pump coronary artery bypass [OPCAB]) has been suggested by some to reduce postoperative neurologic events in elderly patients. ${ }^{1,2}$ Moreover, manipulation of the aorta has been suggested to be associated with higher postoperative neurologic events as well. $^{3-5}$ As a result, several devices were designed to reduce aortic manipulation during surgical myocardial revascularization..$^{6-8}$ The Heartstring proximal anastomotic system (Guidant, Indianapolis, Ind) is such a device.

This article summarizes our initial experience with the Heartstring system and emphasizes some tips and tricks for its use.

\section{Materials and Methods}

Twelve consecutive patients, who underwent OPCAB and were found to have a diseased aorta, had their proximal anastomoses performed with the assistance of the Heartstring device. Patients' preoperative characteristics were collected according to the EuroSCORE predictive model definitions ${ }^{9}$ and were used to calculate both the perioperative standard ${ }^{9,10}$ and logistic ${ }^{11,12}$ expected mortalities. 

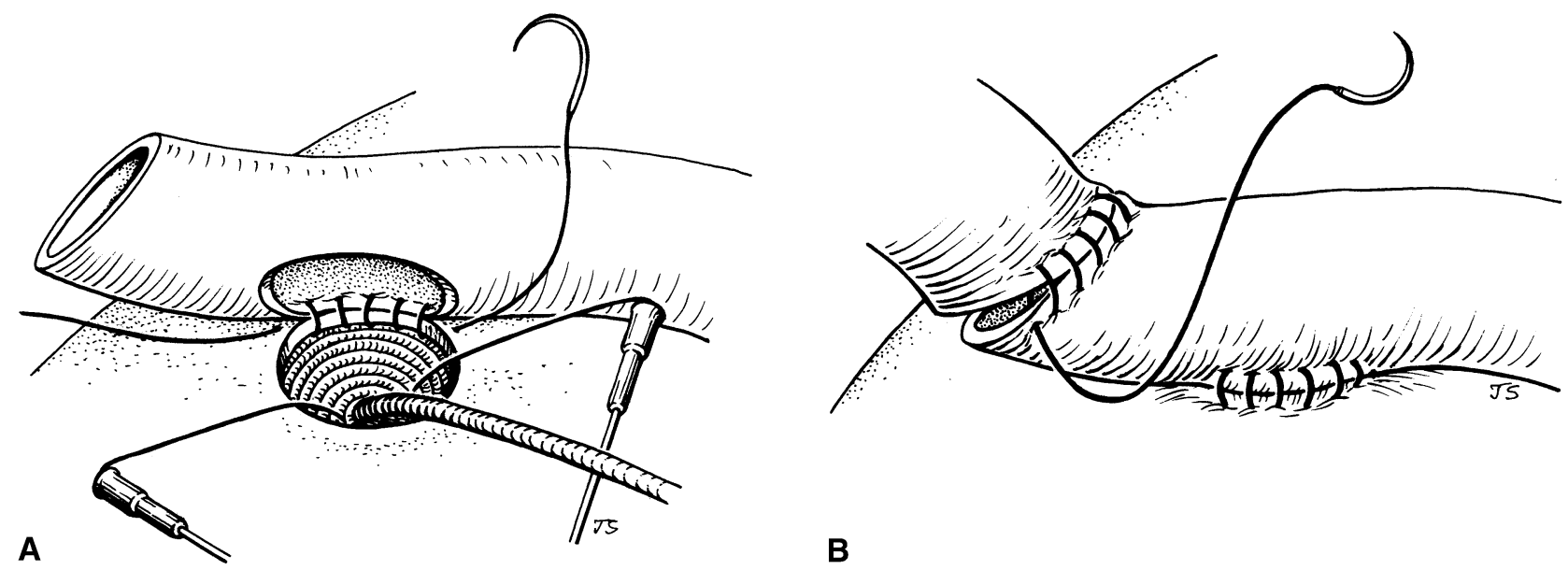

Figure 1. "Horseshoe" side-to-side anastomosis $(A)$ and a beveled end-to-end anastomosis between the proximal part of the anastomosed conduit to another conduit (B).

\section{Surgical Technique}

After mid-sternotomy, the left internal thoracic artery (LITA) simultaneously with the left radial artery or the greater saphenous vein graft (SVG) were harvested. A full heparin dose was administered. The ascending aorta was assessed by gentle palpation according to the technique described by Mills and Everson ${ }^{13}$ or with the aid of transesophageal or epiaortic ultrasound grading the aortic disease on a scale of I to V. ${ }^{14,15}$ In all patients, the aorta was found to be at least grade IV and judged to be diseased to such an extent that would endanger the likelihood of embolization if a partial clamp were to be used. The distal anastomoses were performed first, with the aid of a suction-assisted stabilizer and an apical suction device. The LITA was anastomosed to the left anterior descending artery in all cases and was performed first. After the distal anastomoses were completed, the proximal anastomoses were performed with the assistance of the Heartstring device.

\section{Proximal Anastomosis Technique}

For the placement of the proximal anastomosis, the aorta was assessed for an anterior circular segment of normal aorta with a diameter of approximately $1 \mathrm{~cm}$. This assessment can be performed by gentle palpation, transesophageal echocardiography, epicardial echocardiography, or a combination of all of these.

The device is generally used according to the manufacturer instructions with some modifications. We found that immersing the seal in a bucket filled with normal saline at a temperature of approximately $50^{\circ} \mathrm{C}$ for 5 minutes before loading reduces the likelihood of cracks or unravels in the seal. The warm seal enhances and secures the manipulation and loading of the device. A 6-0 Prolene with a half-circle needle (W8815, Ethicon, Somerville, $\mathrm{NJ}$ ) is our preferred suture. Because the distance between the edge of the seal and the outer part of the aortic hole is approximately 0.5 $\mathrm{cm}$, the half-circle needle is easier to manipulate and reduces the likelihood of suturing the seal. A blower/mister is used to clear the field of oozing blood during the suturing.

\section{Proximal Anastomosis Options}

The technique suggested by the manufacturer is standard end-toside anastomoses between a conduit and the aorta, using a new Heartstring device for each anastomosis. To perform proximal arterial anastomoses or to use only 1 hole on the aorta, we used 3 different modified techniques: (1) a standard end-to-side anastomosis between a conduit and the aorta, and then an end-to-side anastomosis between a second conduit to the first conduit ( $\mathrm{T}$ graft); (2) a "horseshoe," side-to-side anastomosis, between a conduit and the aorta (Figure 1, $A$ ), and then a beveled end-to-end anastomosis between the proximal part of the anastomosed conduit to another conduit as long as the proximal part of the anastomosed conduit is valveless (Figure 1, B); and (3) a standard end-to-side anastomosis between a conduit and the aorta, but at the end of the anastomosis, the seal is left in place and the last suture is left untied (Figure 2, $A$ ). An incision is made on the hood of the anastomosed conduit, and a second conduit is anastomosed to the hood of the first one (Figure 2,B). After the completion of the second anastomosis, the seal is removed and the suture of the first proximal anastomosis is tied.

After completion of the proximal anastomoses, the heparin is reversed, hemostasis is performed, and the chest is closed in a normal fashion.

Data on the operative and postoperative courses were collected until the patient was discharged from the hospital.

\section{Results}

The preoperative characteristics of the patients are presented in Table 1. No preoperative neurologic history was present. There were no postoperative neurologic events or perioperative mortality in this group of patients despite high expected mortality according to the EuroSCORE predictive model, both the additive $(8 \% \pm 3 \%)$ and logistic models $(12 \% \pm 8 \%)$. The number of distal anastomoses performed per patient ranged between 2 and 3 with a median of 3 . All patients received the LITA to the left anterior descending 

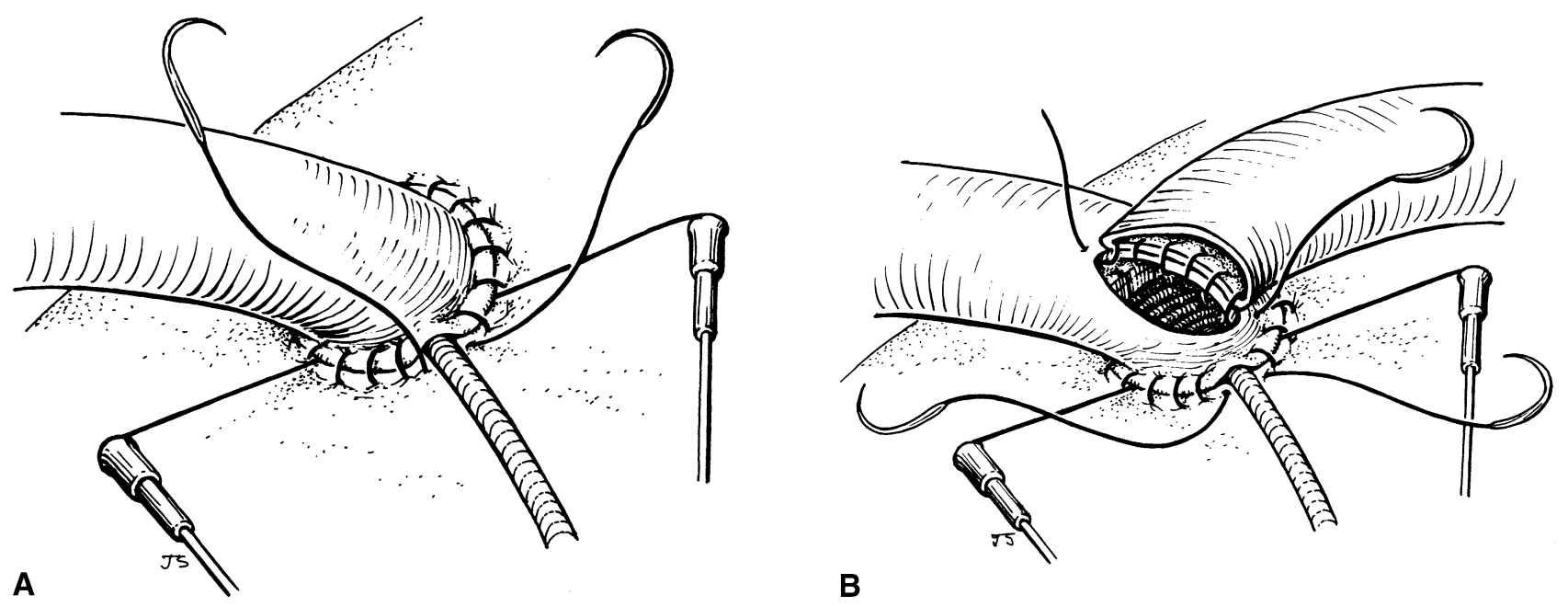

Figure 2. A complete untied standard end-to-side anastomosis with the seal in place $(A)$ and a second conduit anastomosed to the hood of the first one (B).

artery. In 5 patients the radial artery was used as a conduit and connected proximally to the LITA as a Y graft, to an SVG as a "horseshoe," or on the hood of an SVG. The SVG was used for all other targets and connected proximally to the aorta with the Heartstring device. When more than 1 proximal SVG anastomosis was required, it was connected to the first SVG in one of the modified techniques described earlier. The operative and postoperative courses of all patients were uneventful with no major sequelae, except 1 patient required a pacemaker implantation for sick sinus syndrome. The length of stay ranged from 5 to 13 days with a median of 7 days. The patient who stayed 13 days required the pacemaker implantation. During the performance of the anastomosis with the Heartstring, there is a continuous oozing of blood that may increase the amount of blood transfusions. The preoperative and immediately postoperative hemoglobin levels were $12.5 \pm 1.3 \mathrm{~g} / 100 \mathrm{~mL}$ and 10.7 $\pm 1.3 \mathrm{~g} / 100$, respectively. The patients were transfused with a median of 1 unit of packed red blood cells during the operation (range: 1-2). In contrast, we reviewed 12 patients who underwent $\mathrm{OPCAB}$ without the use of the Heartstring device in the same period of time and found that most of them were not transfused during the operation (median: 0, range: 0-1) (Mann-Whitney $U$ test: $P=.02$ ).

\section{Device Failure}

Three seals developed cracks during the loading procedure in the first 2 cases and were not used. One seal developed an unravel in its periphery; nevertheless, it was used successfully, but with higher than usual bleeding.

\section{Discussion}

This article describes our initial experience with the Heartstring proximal anastomotic system. Despite the fact that
TABLE 1. Patients' preoperative characteristics

\begin{tabular}{|c|c|c|}
\hline Characteristic & & $\begin{array}{c}\text { Patients } \\
\text { ( } N=12)\end{array}$ \\
\hline Age (y) & & $76 \pm 7$ \\
\hline Female gender & & $42 \%$ \\
\hline Hypertension & & $67 \%$ \\
\hline COPD & & $42 \%$ \\
\hline LVEF \% & & $37 \pm 9$ \\
\hline Poor LV & & $25 \%$ \\
\hline Recent MI & & $33 \%$ \\
\hline Unstable angina & & $50 \%$ \\
\hline Emergency & & $8 \%$ \\
\hline Predicted EuroSCORE mortality & Standard \% & $8 \pm 3$ \\
\hline & Logistic \% & $12 \pm 8$ \\
\hline
\end{tabular}

Data are presented as mean \pm SD for continuous variables and as percentage for noncontinuous variables.

$C O P D$, Chronic obstructive pulmonary disease; $L V E F$, left ventricular ejection fraction; Poor $L V$, poor left ventricular function (ejection fraction $<$ $30 \%)$; Recent $M I$, recent myocardial infarction $(<90 \mathrm{~d})$.

the patients described here were high-risk patients (expected perioperative mortality of $12 \% \pm 8 \%$ according to the EuroSCORE logistic predictive model), their operative and postoperative courses were uneventful. In fact, an 84-yearold woman with moderate left ventricular function who had a recent myocardial infarction and who underwent an emergency operation had expected additive and logistic mortalities of $11 \%$ and $25 \%$, respectively. All of these patients had severely diseased aortas. In such situations, if the decision is to avoid manipulation of the aorta, few alternative options are available. One alternative is to partially revascularize the heart in such a way that will avoid manipulation of the aorta altogether. Another option is to perform a complete arterial revascularization using multiple in situ arterial conduits 
without manipulation of the aorta. A third option is to attach free arterial conduits to the LITA as Y or T grafts, or a vein graft to another artery but not the aorta (eg, innominate artery). Except for partial revascularization, the other options are more complex and depend on extensive use of arterial grafts. In high-risk patients with multiple comorbidities, the surgeon sometimes prefers to perform a simpler and faster operation. In such cases, placing the proximal anastomoses on the aorta is advantageous. Several devices have been designed to facilitate the performance of the proximal anastomosis to the aorta with minimal aortic manipulation. ${ }^{6-8}$ They all deploy some kind of metal connector mounted within the vascular conduit into the aortic wall. The advantage of these technologies is in the ability to produce precise, reproducible, and fast proximal anastomoses. However, it is unclear how these devices perform in a diseased aorta with irregular thickness of the aortic wall. The patency rate is an important issue with these devices. The anastomosed conduit must come off of the aorta in a right angle, and it may kink. In addition, the metal connectors may increase neointimal formation and, as a result, stenosis or occlusion. Indeed, Traverse and colleagues ${ }^{16}$ and Carrel and colleagues ${ }^{17}$ observed significant rates of stenosis in the vein grafts close to the connector site shortly after the operation when using the Symmetry proximal anastomotic device (St Jude Medical, Inc, St Paul, Minn).The proximal anastomoses with these devices must be performed before distal anastomoses, which makes the proper length measurement of the conduit more difficult. It seems that refinements of these technologies and longer follow-up times are necessary before those devices will gain increasing popularity.

The Heartstring proximal anastomotic device uses a different approach. It allows the surgeon to perform the anastomosis using standard techniques in a clampless environment. As a result, each bite can be placed appropriately whether the aorta is normal, thick, or irregular. In addition, the patency rate theoretically should not be different from standard anastomoses performed without the device. The surgeon can decide the proper sequence of anastomoses, proximal or distal first, according to his or her preference.

However, several limitations exist with the Heartstring system as well.

\section{Bleeding}

The seal does not give a complete bloodless field. A continuous oozing of blood was present in all cases and seemed to be blood-pressure dependent. Tozzi and colleagues ${ }^{18}$ used the Heartstring device for performing proximal anastomoses in 3 sheep that underwent OPCAB. They found the leakage to be $3 \pm 0.5 \mathrm{~mL} / \mathrm{min}$ with a blood pressure of $120 / 65 \mathrm{~mm} \mathrm{Hg}$ and $9 \pm 1.5 \mathrm{~mL} / \mathrm{min}$ with a blood pressure of 200/95 mm Hg. ${ }^{18}$ We found it difficult to assess directly the amount of bleeding during the performance of the proximal anastomosis with the Heartstring device because of interference caused by an unknown amount of oozing from the sternum, mediastinal fat, and additional saline introduced to the surgical field by the blower/mister device. We attempted to indirectly estimate blood loss during the procedure by measuring blood-transfused, preoperative, and postoperative hemoglobin in patients who had their proximal anastomosis performed with and without the Heartstring device. Although the cause of intraoperative bleeding depends on many factors (eg, number of distal and proximal anastomoses), it is our impression that a significant amount of blood is lost during the use of the Heartstring device. The addition of a cell saver to the operation seems to be mandatory to reduce the amount of allogenic blood transfused. In addition, systemic blood pressure should be kept as low as possible during the performance of the proximal anastomoses to reduce blood loss and increase visibility. There may be rare cases of increased bleeding that obscures the operative field and that cannot be sufficiently cleared by the blower/mister or of device failure that prevents the anastomosis from being performed safely. In these cases, if the surgeon believes that partially clamping the aorta is too hazardous, the anastomosis can be closed with a pledgeted $\mathrm{U}$ stitch, the Heartstring can be removed, and an alternative site for placement of the proximal anastomosis can be considered. In our experience thus far, no such situation has occurred.

\section{Technical Failures}

Because of the relative inflexibility of the seal in the first 2 cases, cracks appeared in the seal during the process of loading, which prevented us from using it. The process of seal loading seemed to be unpredictable. Subsequently, after immersing the seal in warm water, the loading procedure became easier and more predictable, and no cracks appeared thereafter. Nevertheless, in 1 case, despite warm water immersion, a minor unravel in the periphery of the seal was identified. The seal was used successfully, although the field was bloodier.

\section{Anastomotic Size}

The aortic hole currently is relatively large $(4.5 \mathrm{~mm})$ and not suitable for most arterial grafts. An alternative approach has been suggested in this article that can overcome this limitation. Although theoretically, smaller Heartstring devices can be manufactured to allow the placement of arterial conduits directly on the aorta, the relatively inflexible seal does not seem to easily fit smaller delivery systems unless the seal is decreased significantly in size, a situation that will increase the difficulty of the anastomosis. 


\section{Cost}

The Heartstring proximal anastomotic device is a relatively expensive device. Its cost is approximately equivalent to the cost of 1 hospitalization day. It certainly increases the cost of the procedure. However, if the use of this device in selected high-risk patients decreases postoperative neurologic complications, which definitely increase the length of hospitalization and complexity of treatment, it will probably prove to be markedly cost-effective.

\section{Conclusion}

The Heartstring proximal anastomosis system is a device that allows the surgeon to safely perform proximal, clampless anastomoses especially in elderly patients with a diseased aorta. Further prospective studies with long-term follow-up are required.

\section{References}

1. Ricci M, Karamanoukian HL, Abraham R, Von Fricken K, D'Ancona G, Choi S, et al. Stroke in octogenarians undergoing coronary artery surgery with and without cardiopulmonary bypass. Ann Thorac Surg. 2000;69:1471-5.

2. Demaria RG, Carrier M, Fortier S, Martineau R, Fortier A, Cartier R, et al. Reduced mortality and strokes with off-pump coronary artery bypass grafting surgery in octogenarians. Circulation. 2002;106(12 Suppl 1):I5-10.

3. Barbut D, Hinton RB, Szatrowski TP, Hartman GS, Bruefach M, Williams-Russo $\mathrm{P}$, et al. Cerebral emboli detected during bypass surgery are associated with clamp removal. Stroke. 1994;25:2398-402.

4. Ura M, Sakata R, Nakayama Y, Goto T. Ultrasonographic demonstration of manipulation-related aortic injuries after cardiac surgery. $J \mathrm{Am}$ Coll Cardiol. 2000;35:1303-10.

5. Calafiore AM, Di Mauro M, Teodori G, Di Giammarco G, Cirmeni S, Contini M, et al. Impact of aortic manipulation on incidence of cerebrovascular accidents after surgical myocardial revascularization. Ann Thorac Surg. 2002;73:1387-93.

6. Calafiore AM, Bar-El Y, Vitolla G, Di Giammarco G, Teodori G, Iaco
AL, et al. Early clinical experience with a new sutureless anastomotic device for proximal anastomosis of the saphenous vein to the aorta. J Thorac Cardiovasc Surg. 2001;121:854-8.

7. Antona C, Scrofani R, Lemma M, Vanelli P, Mangini A, Danna P, et al. Assessment of an aortosaphenous vein graft anastomotic device in coronary surgery: clinical experience and early angiographic results. Ann Thorac Surg. 2002;74:2101-5.

8. Eckstein FS, Bonilla LF, Englberger L, Immer FF, Berg TA, Schmidli J, et al. The St Jude Medical symmetry aortic connector system for proximal vein graft anastomoses in coronary artery bypass grafting. J Thorac Cardiovasc Surg. 2002;123:777-82.

9. Roques F, Nashef SA, Michel P, Gauducheau E, de Vincentiis C, Baudet E, et al. Risk factors and outcome in European cardiac surgery: analysis of the EuroSCORE multinational database of 19030 patients. Eur J Cardiothorac Surg. 1999;15:816-22.

10. Nashef SA, Roques F, Hammill BG, Peterson ED, Michel P, Grover FL, et al. Validation of European System for Cardiac Operative Risk Evaluation (EuroSCORE) in North American cardiac surgery. Eur J Cardiothorac Surg. 2002;22:101-5.

11. Michel P, Roques F, Nashef SA. Logistic or additive EuroSCORE for high-risk patients? Eur J Cardiothorac Surg. 2003;23:684-7.

12. Roques F, Michel P, Goldstone AR, Nashef SA. The logistic EuroSCORE. Eur Heart J. 2003;24:881-2.

13. Mills NL, Everson CT. Atherosclerosis of the ascending aorta and coronary artery bypass. Pathology, clinical correlates, and operative management. J Thorac Cardiovasc Surg. 1991;102:546-53.

14. Ribakove GH, Katz ES, Galloway AC, Grossi EA, Esposito RA, Baumann FG, et al. Surgical implications of transesophageal echocardiography to grade the atheromatous aortic arch. Ann Thorac Surg. 1992;53:758-61.

15. Wilson MJ, Boyd SY, Lisagor PG, Rubal BJ, Cohen DJ. Ascending aortic atheroma assessed intraoperatively by epiaortic and transesophageal echocardiography. Ann Thorac Surg. 2000;70:25-30.

16. Traverse JH, Mooney MR, Pedersen WR, Madison JD, Flavin TF, Kshettry VR, et al. Clinical, angiographic, and interventional follow-up of patients with aortic-saphenous vein graft connectors. Circulation. 2003;108:452-6.

17. Carrel TP, Eckstein FS, Englberger L, Windecker S, Meier B. Pitfalls and key lessons with the symmetry proximal anastomotic device in coronary artery bypass surgery. Ann Thorac Surg. 2003;75:1434-6.

18. Tozzi P, Corno AF, Locca D, Von Segesser LK. The Heartstring: a new tool to avoid aortic side clamping. Heart Surg Forum. 2003; 6(Suppl 1):S38.

\section{Authoritative}

The Journal of Thoracic and Cardiovascular Surgery is the most frequently cited thoracic/cardiovascular surgery journal in the Science Citation Index. An article in JTCVS is cited on average almost twice as often as those in the closest cardiothoracic journal. 